\title{
Through the decreased values gap to increased organizational effectiveness: The mediating role of organizational commitment
}

\begin{abstract}
The purpose of this paper is to clarify whether congruence between espoused and attributed organizational values (CEAOV) in contemporary business circumstances is a necessity or just "nice to have". Accordingly, two objectives are formulated: (1) to investigate whether CEAOV has a direct impact on organizational effectiveness, and (2) to assess the mediating effect of organizational commitment between CEAOV and organizational effectiveness. The research was conducted within 15 Croatian companies $(n=523)$. Data were collected through content analysis of the official websites of the companies, surveys of employees, semi-structured interviews with the members of top management and analysis of publicly available financial reports. A conceptual model is proposed regarding the mediating effect of organizational commitment on the impact of the espoused-attributed value fit on effectiveness. Structural equation modelling (SEM) was used for the analysis. The results show that CEAOV positively affects organizational effectiveness through the mediation of organizational commitment. The only path to attaining effectiveness is through commitment. No direct effect is found. Our research sheds light on the relevant role of authenticity, in the light of value congruence, in every organization. When employees and organizations live their values to the same degree, there is an impact on organizational commitment and hence on organizational effectiveness.
\end{abstract}

Keywords: Organizational values, Espoused values, Attributed values, Value congruence, Organizational effectiveness, Organizational commitment 


\section{Introduction}

The process of globalization, followed by constant technological progress, has made not only information, but also specific knowledge and skills easily accessible. Today it is quite common for companies to follow the latest market trends and have efficient production and well-defined business processes. Furthermore, in today's highly complex and competitive environment, all these matters are in some way prerequisites for survival in the market. However, practice shows that instead of focusing attention primarily on traditional factors of organization, such as the division of work, hierarchy, discipline, centralization, etc., some new concepts are gaining more importance. Among these are organizational values, which today present an important field of research and business practice.

Organizational values can be defined as basic principles that guide all organizational activities (Lencioni 2002). They emphasize what the company stands for and takes pride in, but also describe the characteristics of a particular organization, guiding organizational behavior and serving to distinguish one organization from another (Williams 2002). Kanter (2008) claims that organizational values are the key ingredient in contemporary organizations as they are able to connect seemingly drastically different people in such a way that they act together in achieving the organizational purpose.

Although the importance of organizational values has already been well researched, some dimensions of organizational values are still under-researched. Special attention is paid in this paper to the importance of espoused organizational values and their congruence with attributed organizational values, which is a prerequisite for organizational authenticity. Hultman (2005) compared organizations to "ships on a stormy sea, battered on all sides by the winds of change" and in that context, values serve as a compass: if they are congruent and authentic, "organizational leaders can help individuals, teams and organizations successfully navigate the rough waters through which they must pass" (Hultman 2005, p.43). One might consider that there is no dispute regarding this, but the latest business practice offers examples (e.g. the case of Volkswagen) that demonstrate the consequences of a mismatch between espoused and attributed organizational values. With this paper, we therefore want to rethink the necessity of congruence between espoused and attributed organizational values (CEAOV), which is no longer a prerequisite "only" for organizational authenticity, but also for the existence of the organization. 


\section{Theoretical background and hypotheses}

\section{Relevance and role of espoused and attributed organizational values}

The most commonly used classification of organizational values concerns espoused and attributed as two specific categories of values. Argyris and Schön (1978) were among first to distinguish two different theories, i.e. espoused theory related to organizational practices that exist in every organization and theory-in-use, which may be incongruent. Ostroff et al. (2003) clearly divided organizational values into two categories: espoused and enacted values, the latter of which we call attributed values as suggested by Bourne and Jenkins (2013).

Espoused values are those that we first encounter when we come into contact with an organization, because they are usually publicly available - mostly on the organization's official website and in the company's annual reports. They help organizations in creating implicit contracts with their customers, suppliers and shareholders, as well as with all other stakeholders (Cording et al. 2014). Espoused values serve as a communication tool through which top management shape the behavior of employees (Jonsen et al. 2015), clearly suggesting to them what the organization especially appreciates and - indirectly - what forms of organizational behavior are not desirable. If they are well developed and communicated, but also combined with good recruiting practice, they may help in reducing employee turnover and recruitment costs for the company (Cennamo and Gardner 2008). The need to define espoused organizational values was best highlighted by Covey (2002, p.28), who explained it very simply: “unless you institutionalize your values, they won't happen". One recent study even indicated that espoused organizational values are positively associated with the financial performance of the company (Jonsen et al. 2015). Finally, even if espoused values serve no other organizational purpose, "they would still serve as motivational tools because they offer people a basis for engagement with their work, a sense of membership, and an anchor of stability in the midst of constant change" (Kanter 2008, p.50).

In contrast to espoused values, which often stand for "what we want to be", attributed values stand for "what we are" (Soyer et al. 2007). Attributed values, or as some call them "enacted", or "actual" values, are those values that employees generally regard as representative of the organization for which they work, i.e., they represent the attributes of the organization as employees see (Bourne and Jenkins 2013). Attributed values actually govern the behavior of employees - only attributed values are exhibited on the surface through organizational norms and organizational behavior 
(Arbour et al. 2014) because employees perform their activities not according to judgments of top management, usually responsible for defining espoused values, but rather according to their own judgments of the values that are present in the organization.

In this study, we focus on the fit between the espoused and attributed values of an organization and the impact of this fit on business performance. Specifically, the question we raise is whether CEAOV is related to the overall level of organizational commitment and - even more importantly - to the overall level of organizational effectiveness as a comprehensive and ultimate measure of organizational success. Studies have indicated that reducing the gap between espoused and attributed organizational values may influence the business in a positive way. However, the impact of CEAOV on organizational effectiveness, as an overall measure of business success, is not easy to measure and has therefore not been adequately researched in the past. Hence, the value of this article lies in contributing to a better understanding of CEAOV, not only in terms of increasing organizational commitment, because it is not the final and ultimate organizational goal, but in achieving long-term organizational success.

\section{Mismatch between espoused and attributed values - organizational consequences}

Top managers prefer their organizations to be well aligned, meaning that their activities, organizational units and all other aspects of the organization are congruent. However, our knowledge of the relationship between espoused values and the way in which they are understood and lived by employees, together with its organizational consequences, is still limited (Shapiro and Naughton 2015). This provides the motivation for this research because we also want to shed light on the role of espoused values in business. This is even more necessary because today it is common practice, as has already been indicated above, for business organizations to espouse their values publicly, but at the same time many of them "fail to turn the values they espouse into tangible reality" (Thornbury 2003, p.71).

Managers have a crucial role in reducing the value gap because the examples they set through their behavior should reflect exactly the espoused organizational values. They should therefore be cautious in communicating the values of the organization, ensuring that they live these values before espousing them, "as such walking the talk and talking the walk are two sides of the same 
authenticity coin" (Cording et al. 2014, p.52). Declarative promotion of organizational values and not living them inside the company could therefore result in several serious organizational consequences: the best employees could leave the company, morale could plummet and the company may well not get the most out of its employees as they'll be spending time carping about management saying one thing and doing another (Brinckerhoff 2009).

The organizational consequences of a mismatch between espoused and attributed organizational values can affect the most important elements of the organizational culture. Such discrepancy can greatly influence the creation of a climate of mistrust and suspicion (Hultman and Gellermann 2002) and the potential outcomes of such discrepancies can affect not only the organization as a system, but also its employees and their behavior within the organization (Clarke 1999; Ostroff et al. 2003; Porter 2013). Finally, espoused and attributed values should be consistent because this determines whether the mission (statement) achieves its fundamental purpose, i.e. motivating the employees (Babnik et al. 2014), or is just a hollow statement which does not touch the hearts of employees and is only a showpiece (Panda and Gupta 2003). Schuh and Miller (2006) therefore claim that reducing the mismatch between espoused and attributed values not only avoids the loss of organizational credibility, but also strengthen organizational reputation and the company's external legitimacy.

As organizations are composed of human beings, they can, like individuals, be more or less authentic. Indeed, "one reason often articulated for why authenticity is missing in many organizations is that individuals and organizations are not living their values" (Auster and Freeman 2013, p.40). Cording et al. (2014) define the concept of organizational authenticity as consistency between espoused organizational values and realized organizational practices, while Hultman (2005, p.43) links it to organizational behavior, defining it as "the degree to which values are expressed - verbally and behaviorally - in a genuine, sincere manner". The interplay between these two types of values, with potential conflicts, is shown in Figure 1. The zone of conflict appears when there is a mismatch between espoused and attributed organizational values in four different ways. Note that the Figure 1 also shows in the vertical dimension how values are transferred from the theoretical field to the behavioral field, reading from top down. 


\section{INSERT FIGURE 1 ABOUT HERE}

Finally, the whole story about aligning espoused and attributed values will be meaningless if values do not make a difference to how the organization lives and acts its everyday practice. Thornbury (2003, p.70) thus highlights that espoused values, however well-chosen they might appear, "will only make a difference when: (i) they are shared by all in the organization, (ii) they state what is authentically believed, (iii) they guide day-to-day behavior at work, and (iv) they are fully integrated into the business strategy, processes and decisions".

\section{Research model}

Panda and Gupta (2003) analyse the gap between what is espoused in the organization and what is prevailing and really alive in the organization. They conclude that the greater the gap, the weaker the commitment, which therefore contributes to employees' dissatisfaction. More recently, Howell et al. (2012) have expressed this notion in a positive way: commitment is higher when espoused and attributed organizational values are congruent. These findings suggest that when employees perceive that organizational authenticity is maintained, their commitment to the organization is enhanced. Such findings are consistent with the idea that employees' faith and trust in the organization's authenticity depends on the conformity observed between what the organization says and what it is perceived the organization does. In the same vain, Ortega-Parra and SastreCastillo (2013) also found that a higher CEAOV has a positive relationship with commitment. All in all, the above allows us to pose the first hypothesis:

Hypothesis 1: Congruence between espoused and attributed organizational values (CEAOV) has a positive effect on organizational commitment.

In turn, organizational commitment is shown to affect organizational effectiveness: the higher the commitment, the greater the organizational effectiveness. Numerous studies on management standards has shown the positive impact of the commitment of the leadership and people of the organization on processes and on performance indicators. This is shown in the relationships 
between the criteria in the European Foundation for Quality Management (EFQM) model. Drawing on this evidence, the second hypothesis is:

Hypothesis 2: Organizational commitment has a positive effect on organizational effectiveness.

Finally, a vein of research has demonstrated the relationship between CEAOV and organizational effectiveness. As early as the beginning of the 1980s, some well-known scholars claimed that companies devoted to their values are more successful in achieving excellence in business results (Peters and Waterman 1982; Woodcock and Francis 1989). Since these pioneering studies on this topic, some authors have explored the relationship in greater detail, analysing certain particular related issues. Thus, Voss et al. (2006), for example, found that when two top leaders responsible for different organizational units disagree about the organizational identity, organizational performance worsens. More recently, Cording et al. (2014) also found that "a lack of organizational authenticity", i.e. consistency between a firm's espoused values and realized practices, "is associated with lower productivity, which in turn is related to long-term merger performance, thus affecting outcomes for shareholders". The third and last hypothesis is:

Hypothesis 3: Congruence between espoused and attributed organizational values (CEAOV) affects positively on organizational effectiveness.

These hypotheses are shown together in the research model (Figure 2). The model suggests there is a meditation effect of organizational commitment between CEAOV and organizational effectiveness, which will also be analysed.

\section{Methodology}

\section{Measurement scales}

Value fit can be measured in many different ways, while the most commonly used approaches are difference scores (the sum of differences, the sum of absolute values of the differences and the sum of the squared differences) or correlations between individual and organizational value items. Our study measures the CEAOV using two analysis levels - espoused values were assessed at the organizational level, whereas attributed values were assessed at the individual level. Consequently, 
our research can be considered as across-level analysis. We consider the espoused values drawing on the company's official website (not the perception of the espoused values held by employees). The attributed values were obtained as the employees' perceptions of shared values. We consider this method an original and sound approach for measuring the CEAOV of the company.

Specifically, our research was conducted within 15 Croatian companies, the espoused and attributed values of which were assessed. The espoused organizational values were obtained through content analysis of those parts of the official websites of the companies in which organizational values are explicitly stated. In the past, CEAOV has predominantly been measured using generic value taxonomies (McDonald and Gandz 1992; Schwartz 1992), in which individual values are clustered into different categories of values. However, business practice has evolved significantly and thus today some other criteria are more suitable for differentiating organizational values than at the end of $20^{\text {th }}$ century. For this reason, as the basis for classifying values into different categories we used a mission-based model of organizational values (Malbašić et al. 2015), according to which organizational values are classified into following categories:

a) relational values - promote quality in interpersonal relations primarily among employees;

b) development values - aimed at differentiating and continuously improving the company;

c) business values - values that refer to the organization's business and profit-making activity;

d) contribution values - aimed at doing more for stakeholders than is strictly required by the business relationship.

The attributed values were collected through an employee survey and classified into the four groups already mentioned. The differences between espoused and attributed values were finally computed. Table 1 shows the 28 value items and codes.

INSERT TABLE 1 ABOUT HERE

The basis for data collection concerning organizational effectiveness was Balanced Scorecard (BSC) model (Kaplan and Norton 1996). For the purpose of this study, we defined 20 generic key performance indicators (KPIs); five for each of the four BSC perspectives, as follows: 
a) Financial - Income growth rate, Net profit margin, Business efficiency, Return on investment, Credit rating;

b) Customers - Market share, Customer satisfaction, Customer retention, New customer acquisition, Customer relationship;

c) Internal business processes - Quality of products/services, New product introductions, Level of capacity use, Work productivity, Response time;

d) Learning and growth - Employee satisfaction, Employee productivity, Information systems capabilities, Continuous improvement of processes, Education and training of employees.

In order to assess as objective overall level of organizational effectiveness as possible, data were collected through three different sources: the first source was the questionnaire, in which all surveyed respondents from all analysed companies estimated several items concerning organizational effectiveness; the second source was publicly available databases with some typical financial information on the companies studied; the third source was semi-structured interviews conducted with the members of top management of each analysed company. Finally, we combined information from all three data sources, thus trying to avoid the risk of one-sided effectiveness assessment, considering that effectiveness assessment from the side of top management and other employees is often significantly different.

Finally, organizational commitment items were also collected by surveying employees. Meyer et al. (1993) proposal was used, resulting in an array of 18 items organized a priori under three dimensions, each representing one of the three components of organizational commitment affective, normative and continuance.

\section{Sample}

The sample for the questionnaire was based on a wide group of companies from different industries. The data collection began in the second half of 2013 and ended in mid-2014. The questionnaire, which served as the basis for the employee survey, included several sections. After examining all completed questionnaires, a total of 523 valid responses were obtained (Table 2). 


\section{INSERT TABLE 2 ABOUT HERE}

\section{Method}

The analysis was performed in five steps: (i) the measurement of CEAOV; (ii) the definition and assessment of organizational effectiveness; (iii) the definition and computation of the commitment construct; (iv) assessment of the reliability and validity of the construct analysed; (v) the proposal of the model for the impact of CEAOV on effectiveness, taking account of the mediating effect of organizational commitment, using structural equation modelling (SEM) in EQS 6.2 software.

\section{Results}

\section{Measurement of congruence between espoused and attributed organizational values (CEAOV)}

The first step consists of assessing the measurement scales. The independent variable of the model $(\mathrm{CEAOV})$ is the difference between total espoused values and total attributed values. Previously, the differences between each espoused and attributed values were standardized to avoid bias due to the different metrics.

\section{Measurement of organizational effectiveness}

To examine effectiveness, four variables were calculated, retrieving information from three different sources. Each variable accounts for the degree of effectiveness attained in each of the four BSC perspectives. An exploratory factor analysis (EFA) was conducted with these four variables, yielding only one factor and consequently vouching for the unidimensionality of the construct (see results in Table 3, below). As previously mentioned, the three sources used to calculate the effectiveness variables were: (i) a survey of 523 employees through the questionnaire; (ii) 
interviews with top management of each company (in total, 15 face-to-face, semi-structured interviews); (iii) analysis of publicly available financial reports.

\section{Measurement of organizational commitment}

To assess organizational commitment (the mediator construct in the model), an EFA was performed using 18 items. A Kaiser-Meier-Olkin statistic of 0.912 forecasted a good result for this analysis. A Barlett test also provided the same conclusion $\left(\chi^{2}=3,939.05, p\right.$-value $\left.=0.000\right)$. These results confirmed a linear dependence between the variables and supported our view that the results were sound. Three factors emerged with eigenvalues greater than 1 (Kaiser criterion), which accounted for $55.17 \%$ of the variance in the sample. This scale was analysed in accordance with very strict criteria, greater even than those used by Bernardo et al. (2012), who in turn used Ladhari's (2010) and Wolfinbarger and Gilly's (2003) criteria to retain items. The criteria are that the items (i) load at 0.60 or more on a factor, (ii) do not load at more than 0.35 on other factors and (iii) have an itemto-total correlation of more than 0.40 .

The first factor ("affective commitment") accounts for $37.72 \%$ of the variance and it is formed by 4 items. The second factor ("normative commitment") explains $11.5 \%$ of the variance with two items. Finally, the third factor ("continuance commitment") includes three items and explains $5.95 \%$ of the variance. Table 3 shows in the first three columns the items that were retained according to the aforementioned criteria, including their loads.

\section{Reliability and discriminant analysis of the constructs}

To examine the unidimensionality of the scales of measurements, the reliability of the constructs was assessed (see Table 3). Cronbach's alpha coefficient and composite reliability in most cases exceed the threshold value of 0.7 for internal consistency. The construct "continuance commitment" shows a Cronbach's alpha of 0.622 , below the recommended threshold. However, Malhotra (2004) accepts a minimum criterion of 0.6 to demonstrate internal consistency for some exploratory analyses when the theoretical background is still not settled. Taking the necessary 
caution, the analysis proceeded. In addition, the variance extracted for each factor is greater than 0.5, confirming convergent validity (Fornell and Larcker 1981).

\section{INSERT TABLE 3 ABOUT HERE}

Table 4 provides the results of the analysis of discriminant validity, which was analysed using linear correlations or standardized covariances between latent factors by examining whether the interfactor correlations were less than the square root of the average variance extracted (AVE). Table 4 shows that the square roots of each AVE are greater than the off-diagonal elements (Fornell and Larcker 1981). Discriminant validity is confirmed.

\section{INSERT TABLE 4 ABOUT HERE}

\section{Structural equation model (SEM): Mediating effect of organizational commitment}

A cause-effect model was estimated using the robust maximum likelihood method based on the asymptotic variance-covariance matrix (Figure 2). The fit indices obtained in the measurement model estimation show that the variables converge towards the structure established in the model: $\chi^{2}$ is 285.342 , with 59 degrees of freedom and a $p$-value of $0.000 ; \chi^{2} / \mathrm{df}$ is 4.8 , which is below the acceptable limit of 5. Also, the value of the root means square error of approximation (RMSEA) is 0.086, the confirmatory fit index (CFI) is 0.884 and the goodness-of-fit index (GFI) is 0.925 , demonstrating a moderate but reasonable goodness-of-fit of the model (Hair et al. 1998).

INSERT FIGURE 2 ABOUT HERE 
Table 5 shows that the direct effect ("CEAOV $\rightarrow$ organizational effectiveness") is not significant, while the indirect effect is significant: both paths "CEAOV $\rightarrow$ organizational commitment" and "CEAOV $\rightarrow$ organizational effectiveness" are significant.

INSERT TABLE 5 ABOUT HERE

To proceed, the results of Table 5 are analysed according to the methodology of Baron and Kenny (1986), who argued that three conditions must hold to establish mediation: they establish this through a row of three regressions, which we can express in the following way when SEMs are used:

First, the independent variable CEAOV significantly predicts the mediator "organizational commitment".

Second, the independent variable CEAOV must be shown to predict the dependent variable "organizational effectiveness". This is accomplished as the total effect is 0.183 and significant with a p-value of 3.083 .

Third, the mediator "organizational commitment" must significantly predict the dependent variable "organizational effectiveness".

The three aforementioned conditions are met. Therefore, it is confirmed that "organizational commitment" fully mediates between CEAOV and "organizational effectiveness". The direct effect is not significant; the only significant effect is indirect.

\section{Discussion and managerial implications}

Our research studies the congruence between the values expressed by the organization, i.e. espoused organizational values, and the attributes of the organization as the employees see it, i.e. attributed organizational values. This fit is particularly relevant as it may affect organizational effectiveness. The organization shows behaviors considered appropriate within the organization through espoused values and consequently presents the employee profile through these values. On 
the other hand, attributed values, which are the result of upbringing, experience and the influence of others, actually govern the behavior of employees and their business activities. Our results indicate that this fit affects organizational effectiveness through the mediation of organizational commitment as one of the prerequisites for achieving organizational authenticity.

However, many companies have problems with an imbalance between values at the organizational and individual levels. Currently, a diversity of employees is a common attribute of companies, so extra effort is needed to connect different people working together in order to fulfil the same corporate mission, which is regularly underpinned with organizational values. This conflict could be caused by a misunderstanding of the organizational values or a communication problem with regard to the authentic culture of the company. In this regard, it is relevant for managers to know which type of value mismatch the organization has in order to reduce this gap and its negative consequences. Depending on the type of mismatch, managers will need to plan specific arrangements to resolve the issue. The consequences of such a mismatch can be summarized as follows: (i) loss of talented employees and diminished opportunities to attract a high-performance profile; (ii) the creation of a climate of mistrust and inconsistencies within the company, provoking a decrease in the productivity of employees; (iii) loss of external credibility and reputation. These extremely bad consequences force managers to fight to combat the conflict between espoused and attributed values and increase organizational effectiveness.

Our study has important managerial implications in terms of strengthening the CEAOV. First, leadership is an important factor that enhances the correspondence between the individual and attributed (i.e. enacted) values and the espoused (i.e. formally stated) organizational values. According to Panda and Gupta (2003, p.43), "if the senior executives are in disagreement with the espoused organizational values and among each other, they cannot convince other members in the organization to follow the espoused organizational mission, values or beliefs. This might have affected the cascading or roll-out process of the organizational values and beliefs". The example set by managers plays a crucial role in demonstrating the authenticity of organizational value to employees as their exemplarity is related to authority. According to López (2014), "a manager's exemplarity is the only way to attaining authority. Trust in the intention of the person giving the orders is the only thing that can create authority". Thus, managers have to enhance their authority to develop organizational values through exemplarity of their decisions and actions. 
Second, values have to orient policies and practices in human resource management (HRM). HR managers must include organizational values in their policies and practices, such as employee recruitment and selection procedures, incentive compensation and performance management systems, employee involvement, training and motivational activities (Ballout 2007). For example, if the recruitment process is values-focused, hopefully in the midterm the employees will share these espoused values and congruence will be achieved. In the same way, values can be considered a motivational instrument to engage employees in their daily work and foster a sense of commitment and membership. To increase CEAOV, companies can promote different actions and strategies in the line of Khandelwal and Mohendra (2010, p. 31), who state: "Steps should be taken to hold workshops, training programs, focusing on not only 'what' the values are and their importance, but also the 'how' of achieving them. Further, a strong linkage between the philosophy and systems governing behavior must be created".

Finally, according to Thornbury (2003), managers have to engender strong values assimilated in the daily work and in the process and procedures of the organization. Managers have to transform the values into tangible reality. Organizational culture has to promote openness, continuous improvement and learning. Also, to achieve organizational authenticity, the organization must be one in which people can declare mistakes and still retain their self-worth. All these recommendations for managers will improve CEAOV, organizational commitment and organizational effectiveness.

Overall, our research has shown that CEAOV is one of the prerequisites for achieving organizational authenticity. We demonstrate that congruence between the values that the company explicitly espouses and the company's values as understood by its employees exerts a positive effect on organizational commitment as one of the basic types of job attitude and one of the key variables of organizational behavior. We also demonstrate that CEAOV positively affects the overall level of organizational effectiveness, although that relationship is not direct, but indirect through the mediation of organizational commitment. This research, therefore, further confirms that organizational commitment is a crucial variable, the impact of which on business is extremely important. Managing organizational values in a manner that increases CEAOV can thus significantly help in binding the employees to the organization for which they are working and thus 
not just increase the level of organizational authenticity but also influence the attainment of overall organizational goals. 


\section{References}

Arbour, S., Kwantes, C.T., Kraft, J.M., Boglarsky, C.A. (2014) 'Person-Organization Fit: Using Normative Behaviors to Predict Workplace Satisfaction, Stress and Intentions to Stay', Journal of Organizational Culture, Communications and Conflict, 18(1), 41-64.

Argyris, C., Schön, D.A. (1978) Organizational Learning: A Theory of Action Perspective, Addison-Wesley OD series, Addison-Wesley Publishing Company: Reading, MA.

Auster, E.R., Freeman, R.E. (2013) 'Values and Poetic Organizations: Beyond Value Fit Toward Values Through Conversation', Journal of Business Ethics, 113(1), 39-49.

Babnik, K., Breznik, K., Dermol, V., Trunk Širca, N. (2014) 'The Mission Statement: Organisational Culture Perspective', Industrial Management \& Data Systems, 114(4), 612 627.

Ballout, H.I. (2007) 'Career Success: The Effects of Human Capital, Person-Environment Fit and Organizational Support', Journal of Managerial Psychology, 22(8), 741-765.

Baron, R.M., Kenny, D.A. (1986) 'The Moderator-Mediator Variable Distinction in Social Psychological Research: Conceptual, Strategic, and Statistical Considerations', Journal of Personality and Social Psychology, 51(6), 1173-1182.

Bernardo, M., Marimon, F., Alonso-Almeida, M. del M. (2012) 'Functional Quality and Hedonic Quality: A Study of the Dimensions of E-Service Quality in Online Travel Agencies', Information \& Management, 49(7-8), 342-347.

Bourne, H., Jenkins, M. (2013) 'Organizational Values: A Dynamic Perspective', Organization Studies, 34(4), 495-514.

Brinckerhoff, P.C. (2009) Mission-Based Management: Leading Your Not-for-Profit in the 21st Century, 3rd ed, John Wiley \& Sons: Hoboken, NJ.

Cennamo, L., Gardner, D. (2008) 'Generational Differences in Work Values, Outcomes and PersonOrganisation Values Fit', Journal of Managerial Psychology, 23(8), 891-906.

Clarke, S. (1999) 'Perceptions of Organizational Safety: Implications for the Development of Safety Culture', Journal of Organizational Behavior, 20(2), 185-198.

Cording, M., Harrison, J.S., Hoskisson, R.E., Jonsen, K. (2014) 'Walking the Talk: A Multistakeholder Exploration of Organizational Authenticity, Employee Productivity, and Post-Merger Performance', Academy of Management Perspectives, 28(1), 38-56. 
Covey, S.R. (2002) 'Servant-Leadership and Community Leadership in the Twenty-First Century', in Spears, L.C. and Lawrence, M., eds., Focus on Leadership: Servant-Leadership for the Twenty-First Century, John Wiley \& Sons: New York, NY, 27-33.

Fornell, C., Larcker, D.F. (1981) 'Evaluating Structural Equation Models with Unobservable Variables and Measurement Error', Journal of Marketing Research, 18(1), 39-50.

Hair, J.F., Anderson, R.E., Tatham, R.L., Black, W.C. (1998) Multivariate Data Analysis, Prentice Hall: Englewood Cliffs, NJ.

Howell, A., Kirk-Brown, A., Cooper, B.K. (2012) 'Does Congruence between Espoused and Enacted Organizational Values Predict Affective Commitment in Australian Organizations?', The International Journal of Human Resource Management, 23(4), 731747.

Hultman, K. (2005) 'Evaluating Organizational Values', Organizational Development Journal, 23(4), 32-44.

Hultman, K., Gellermann, B. (2002) Balancing Individual and Organizational Values: Walking the Tightrope to Success, Jossey-Bass/Pfeiffer: San Francisco, CA.

Jonsen, K., Galunic, C., Weeks, J., Braga, T. (2015) 'Evaluating Espoused Values: Does Articulating Values Pay Off?', European Management Journal, 33(5), 332-340.

Kanter, R.M. (2008) 'Transforming Giants', Harvard Business Review, 86(1), 43-52.

Kaplan, R.S., Norton, D.P. (1996) The Balanced Scorecard: Translating Strategy into Action, Harvard Business School Press: Boston, MA.

Khandelwal, K.A., Mohendra, N. (2010) 'Espoused Organizational Values, Vision, and Corporate Social Responsibility: Does it Matter to Organizational Members?', Vikalpa: The Journal for Decision Makers, 35(3), 19-35.

Ladhari, R. (2010) 'Developing E-Service Quality Scales: A Literature Review', Journal of Retailing and Consumer Services, 17(6), 464-477.

Lencioni, P.M. (2002) 'Make Your Values Mean Something', Harvard Business Review, 80(7), $113-117$.

López, J.A.P. (2014) Foundations of Management, Ediciones Rialp: Madrid.

Malbašić, I., Rey, C., Potočan, V. (2015) 'Balanced Organizational Values: From Theory to Practice', Journal of Business Ethics, 130(2), 437-446. 
Malhotra, N.K. (2004) Marketing Research: An Applied Orientation, 4th ed, Prentice Hall: Upper Saddle River, NJ.

McDonald, P., Gandz, J. (1992) 'Getting Value from Shared Values', Organizational Dynamics, 20(3), 64-77.

Meyer, J.P., Allen, N.J., Smith, C.A. (1993) 'Commitment to Organizations and Occupations: Extension and Test of a Three-Component Conceptualization', Journal of Applied Psychology, 78(4), 538-551.

Ortega-Parra, A., Sastre-Castillo, M.Á. (2013) 'Impact of Perceived Corporate Culture on Organizational Commitment', Management Decision, 51(5), 1071-1083.

Ostroff, C., Kinicki, A.J., Tamkins, M.M. (2003) 'Organizational Culture and Climate', in Borman, W.C., Ilgen, D.R. and Klimoski, R.J., eds., Handbook of Psychology: Industrial and Organizational Psychology (Volume 12), John Wiley \& Sons: Hoboken, NJ, 565-593.

Panda, A., Gupta, R.K. (2003) 'Why Mission Statements Become a Show Piece? Case of an IndoAmerican Joint Venture', Vikalpa: The Journal for Decision Makers, 28(2), 23-48.

Peters, T.J., Waterman, R.H. (1982) In Search of Excellence: Lessons from America's Best-Run Companies, HarperBusiness: New York, NY.

Porter, T.J. (2013) Employees'Responses to the Mismatch between Organizations 'Espoused Values and Basic Assumptions about Organizational Culture, $\mathrm{PhD}$ Thesis.

Schuh, A.M., Miller, G.M. (2006) 'Maybe Wilson Was Right: Espoused Values and Their Relationship to Enacted Values', International Journal of Public Administration, 29(9), 719-741.

Schwartz, S.H. (1992) 'Universals in the Content and Structure of Values: Theoretical Advances and Empirical Tests in 20 Countries', Advances in Experimental Social Psychology, 25, 165.

Shapiro, B., Naughton, M. (2015) 'The Expression of Espoused Humanizing Values in Organizational Practice: A Conceptual Framework and Case Study', Journal of Business Ethics, 126(1), 65-81.

Soyer, A., Kabak, Ö., Asan, U. (2007) ‘A Fuzzy Approach to Value and Culture Assessment and an Application', International Journal of Approximate Reasoning, 44(2), 182-196.

Thornbury, J. (2003) 'Creating a Living Culture: The Challenges for Business Leaders', Corporate Governance, 3(2), 68-79. 
Voss, Z.G., Cable, D.M., Voss, G.B. (2006) 'Organizational Identity and Firm Performance: What Happens When Leaders Disagree About "Who We Are?", Organization Science, 17(6), $741-755$.

Williams, S.L. (2002) 'Strategic Planning and Organizational Values: Links to Alignment', Human Resource Development International, 5(2), 217-233.

Wolfinbarger, M., Gilly, M.C. (2003) 'eTailQ: Dimensionalizing, Measuring and Predicting Etail Quality', Journal of Retailing, 79(3), 183-198.

Woodcock, M., Francis, D. (1989) Clarifying Organizational Values, Gower Publishing: Aldershot. 